\title{
Removal of Phenol from Aqueous Solution by Activated Mud*
}

\author{
Zohra Dali-Youcef ${ }^{1}$, Michèle Queneudec ${ }^{2}$ \\ ${ }^{1}$ Laboratory of matérials LABMAT ,Ecole Nationale Supérieure de l'Enseignement Technique \\ d'Oran (ENSET), BP El M'naouer Oran Algeria \\ ${ }^{2}$ Laboratory of Innovantes Technologies, IUT département Génie Civil, avenue des Facultés, Amiens cedex 01 \\ E-mail: zohra_dali2002@yahoo.fr \\ Received May 26, 2011; revised June 24, 2011; accepted July 14, 2011
}

\begin{abstract}
Activated mud has been employed to remove phenolic compounds, a common contaminant in wastewaters. Because of high surface area per unit area, activated mud is the most effective adsorbent and exhibits high capacity of adsorption of phenolic compounds. A complete study was undertaken on the adsorption of phenol starting from an aqueous solution on activated mud with ammonium chloride. The removal is found to be dependent on concentration of phenol and increasing of concentrations favour the uptake. The isotherms and kinetics of adsorption of phenol on activated mud were studied at $20^{\circ} \mathrm{C}$. Equilibrium isotherm of phenol on activated mud is obtained and the results shows that the Langmuir model provided the best fit for the adsorption data. From the experimental results obtained, the adsorption process can be well described with the pseudo-second order model.
\end{abstract}

Keywords: Activated Mud, Adsorption, Phenol, Equilibrium Isotherm, Contaminant

\section{Introduction}

Aromatic compounds like phenol are present in strong concentrations within wastewater generated by the petrochemical industry. This wastewater is often dischargeed into the sea and represents a true danger to human health; it quickly becomes absorbed via all means of exposure. As an example, absorption was estimated at between $70 \%$ and $80 \%$ within 6 hours for exposure to phenol vapour with concentrations ranging from 6 to 20 $\mathrm{mg} / \mathrm{m}^{3}$, practically exclusively by means of skin exposure on healthy volunteers [1]. A number of effective and not very expensive processes have moreover already been developed in order to mitigate the presence of phenol in the environment [2-4].

The present work focuses on testing a new process based on the adsorption of an activated clayey material. A good number of uses for the adsorbing capacity of clay are already known; in the case of polluted water treatment for example, clay can be used to: adsorb organic toxic compounds [5-7], retain surfactant and dyes [8,9], pesticides and herbicides [10] present in the aqueous phase. Clay also gets used in the detergent and paper industries, in oil-well drilling, where it is called drilling sludge after having undergone activation with sodium carbonate [11]. It often proves necessary however to increase capacity of clay by activation [12-15].

Sediments generated from the dredging of dams cause serious environmental problems. Given their abundance throughout the country, the opportunities offered by their reuse seem to be quite attractive. A simple acid activetion of mud has enabled us to derive a material capable of adsorbing potential water pollutants such as phenols.

The material used in the present work contains dam sediments. In Algeria, silting constitutes the major concern of hydraulics engineers and weir facility managers because of its role in reducing dam capacity. For the Fergoug Dam located in Western Algeria, the silting rate reached 78.3\% in 1997. Mud extracted from the dam has been targeted in this study. The sediments there have been submitted to an activation treatment by use of ammonium chloride.

We report here a study on the ability of an activated mud to uptake phenol. To understand the adsorption mechanism and kinetics, phenol removal experiments were carried out. Adsorption isotherms were determined, compared to Langmuir equations, and maximum capacity was calculated. Kinetics of the process including ki- 
netic modeling has been highlighted.

\section{Materials and Methods}

\subsection{Materials}

The dam sediment used in this work is recovered mud from the breach of the Fergoug Dam (located in Western Algeria). The unpurified mud and activated mud with ammonium chloride underwent a physicochemical characterisation.

The chemical composition is given by the fluorescence method using an apparatus of the type FRX P.W1404. RAY. Specific surface has been calculated using the B. E. T. method with an apparatus of the type Micromeri- tics GEMINI 2375.

$\mathrm{X}$-ray diffraction analysis was carried out with a standard Philips PW 3710 x-ray generator with a copper anticathode.

Infrared spectra were obtained on a FT / IR 430 Fourrier transform Infrared spectrometer Jasco. Powder samples were dispersed in anhydrous methylene chloride and drops of the liquid were spread on $\mathrm{KBr}$ plates.

Structure of materials is obtained with electron microscope with sweeping, Philips XL 30.

\subsection{Solutions Preparation}

The solvent used was demineralised water with a $\mathrm{pH}$ of 7 and a conductivity of $0.5 \mu \mathrm{S}$. Phenol adsorption isotherms from aqueous solutions were obtained using the batch equilibration technique: $0.4 \mathrm{~g}$ of adsorbent was mixed with $100 \mathrm{ml}$ of the aqueous solutions of various initial concentration $\left(\mathrm{C}_{0}\right)$ ranges from 2 to $400 \mathrm{mg} / \mathrm{L}$. A mechanical agitator at $500 \mathrm{rpm}$ was used. Suspensions shaken for $2 \mathrm{~h}$, were placed in polypropylene tubes, immersed in a thermostatic shaker bath at constant temperature $20^{\circ} \mathrm{C}$ and then centrifuged. Supernatants collected in dark brown colored bottles were analyzed by a spectrophotometer (Perkin, lamda 25) at the wavelength of maximum absorbance $(1 \max =269.70 \mathrm{~nm})$, then the concentration at stability (Ce) was obtained.

\subsection{Preparation of Activated Mud with $2 \mathrm{M}$ Ammonium Chloride}

About $100 \mathrm{~g}$ of raw mud was mixed to $1 \mathrm{~L}$ of ammonium chloride (2M), solution was agitated during 24 hours at $50^{\circ} \mathrm{C}$. The solution obtained was then introduced into sedimentation test-tube. After 15 minutes of decantation (in order to eliminate large particles like quartz), 2/3 of the remaining volume were recovered and decanted again. The mud was then recovered and washed several times with demineralised water until all chlorides had disappeared. After decantation, the activated mud was dried at ambient temperature and placed in the drying oven between $80^{\circ}$ and $100^{\circ} \mathrm{C}$ in order to undergo the various adsorptions.

\subsection{Adsorption Isotherms}

The physico-phenomenon of adsorption of phenol on acidified mud, is relatively rapid and can be reversible. Several isotherms models were used to describe the equilibrium between adsorbed phenol on acidified mud and phenol in solution (Ce) at constant temperature. The Langmuir isotherm equation is given below:

$$
\mathrm{q}_{\mathrm{e}}=\left[\mathrm{Q}^{0} \mathrm{bCe} 1 / 1+\mathrm{bCe}\right]
$$

where qe is the adsorbed amount $(\mathrm{mg} / \mathrm{g})$ at equilibrium, Ce is equilibrium concentration in the solution $(\mathrm{mg} / \mathrm{L})$, $\mathrm{Q}^{0}$ is the adsorption capacity (mg/g) and b is a constant related to the energy of adsorption $(\mathrm{L} / \mathrm{mg})$.

Death equation is linearised under form [16]

$$
\mathrm{Ce} / \mathrm{qe}=1 / \mathrm{Q}^{0} \mathrm{~b}+\mathrm{Ce} / \mathrm{Q}^{0}
$$

The well-known Freundlich isotherm used for isothermal adsorption is a special case for heterogeneous surface energy in which the energy term in the Langmuir equation varies as a function of surface coverage strictly due to variation of the sorption.

The linear form of Freundlinch isotherm model is given by the following equation:

$$
\ln \mathrm{q}_{\mathrm{e}}=\ln \mathrm{k}_{\mathrm{F}}+(1 / \mathrm{n}) \ln \mathrm{le}
$$

where $k_{F}(m g / g)(1 / m g)^{1 / n}$ and $1 / n$ are Freundlich constants related to adsorption capacity and adsorption intensity, respectively, of the sorbent.

\subsection{Adsorption Kinetics}

The two kinetic models have been studied to deter- mine the phenol elimination mechanism on activated slu- dge. The first model is of the first order, kinetic and conventionally expressed by Lagregen's equation [16]:

$$
\ln ((\mathrm{qe}-\mathrm{qt}) / \mathrm{qe})=-\mathrm{k}_{1} \mathrm{t}
$$

qe: amount of sorbed phenol at equilibrium ( $\mathrm{mg} / \mathrm{g}$ )

qt: amount of sorbed phenol at time t (metal uptake) $(\mathrm{mg} / \mathrm{g})$

$\mathrm{k}_{1}$ : rate constant $\left(\mathrm{min}^{-1}\right)$

The amount of sorbed phenol per gram of adsorbent qt at time $\mathrm{t}$ was caculated as follows:

$$
\mathrm{qt}=\left(\mathrm{C}_{0}-\mathrm{C}_{\mathrm{e}}\right) / \mathrm{m}_{\mathrm{ads}}
$$

$\mathrm{C}_{0}$ : initial concentration of phenol in $\mathrm{mg} / \mathrm{L}$ 
$\mathrm{C}_{\mathrm{e}}$ : concentration of phenol in the fluid at time $\mathrm{t}$ in $\mathrm{mg} / \mathrm{L}$

$\mathrm{m}_{\mathrm{ads}}$ : adsorbent amount in the solution $(\mathrm{g} / \mathrm{L})$

The second model is of the second order and expressed by the following equation [17]:

$$
\mathrm{dqt} / \mathrm{dt}=\mathrm{K}(\mathrm{qe}-\mathrm{qt})^{2}
$$

where $\mathrm{K}$ is the rate constant of sorption (g/mg.mn).

\section{Results and Discussion}

\subsection{Characterization}

The chemical characterization of mud show (Table 1) that silica and calcium oxide are its major constituents. The percentage of the iron oxide is important.

Chemical analysis of mud activated with ammonium chloride indicates a rise in the silica rate as well as the alumina rate which is justified by the literature $[18,19]$. Specific surface of mud activated increases [20,21].

$\mathrm{X}$-ray powder diffraction patterns of raw mud and activated mud are shown in (Figure 1). These XRD confirmed that mud and activated mud was illite [22].

$\mathrm{X}$-ray diffraction pattern for raw mud show : diffracttion peak with basal spacing $d=4.23 \AA$, characteristic of the beidellite; diffraction peak to $3.02 \AA$, characteris- tic of saponite; the diffraction peak at $3.33 \AA$ is assigned to the impurtés as quartz; diffraction peak to $2.12 \AA$ characteristic of illite and diffraction peak to $1.90 \AA$ to kaolin.

Activation of mud causes some change in crystal structure: diffraction peak of quartz at $3.33 \AA$ decreased intensity in comparison to the spectra of diffraction of X-ray of the raw mud; diffraction peak of intensity 100\% situated in $2.73 \AA$ represents the family of the illite, it is essentially about the hectorite or saponite, this last is also put in evidence by the reflection in $1.73 \AA$.

Table 1. Characterization of mud and activated mud.

\begin{tabular}{ccc}
\hline & Mud & Activated mud \\
\cline { 2 - 3 } Constituents & \% by weight & \% by weight \\
\hline $\mathrm{SiO}_{2}$ & 40.98 & 56.95 \\
$\mathrm{CaO}$ & 17.67 & 2.32 \\
$\mathrm{Al}_{2} \mathrm{O}_{3}$ & 8.21 & 13.21 \\
$\mathrm{Fe}_{2} \mathrm{O}_{3}$ & 5.04 & 7.77 \\
Loss on ignition & 25.49 & 18.36 \\
Surface area $\left(\mathrm{m}^{2} / \mathrm{g}\right)$ & 54.58 & 142.36 \\
$\mathrm{pH}$ & 9.48 & 8.4 \\
Density $\left(\mathrm{g} \mathrm{m}^{-3}\right)$ & 2.32 & 2.48 \\
\hline
\end{tabular}

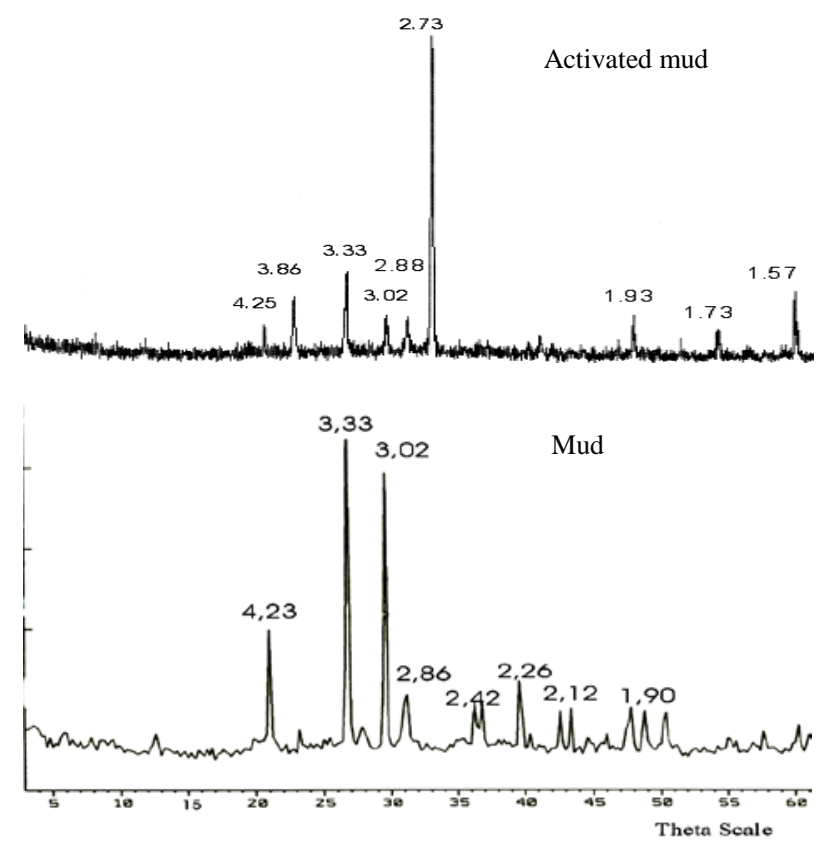

Figure 1. X-ray diffraction pattern for raw mud and activated mud.

The Infrared spectrum (Figure 2) obtained for activeted mud does not differ significantly from its "mother": raw mud. IR analysis of activated mud confirmed the existence of $\mathrm{NH}_{4}{ }^{+}$ion in mud. The band in the range 1400 $1420 \mathrm{~cm}^{-1}$ was attributed to the deformation of $\mathrm{NH}_{4}^{+}$ion, thus further confirming the presence of ammonium in mud [23].

The large band at $1031 \mathrm{~cm}^{-1}$ observed in the spectra of mud, attributed to the vibration of Si-O-Si, decreased intensity in the spectra of the activated mud; it can be du to the formation of the amorphous silica.

The bands around 533 and $469 \mathrm{~cm}^{-1}$, attributed respectively to deformation of four-membered siloxane ring and deformation of Si-O-Al [24,25], increased in the spectra of the acted mud.

The image obtained using the electron microscope with sweeping, Image 1, shows the structure in layers of the rough vase. The image obtained using the electron microscope with sweeping, Image 2, shows the structure of the activated mud.

\subsection{Effect of the Acidified Mud Mass}

Various sample masses from the untreated vase and the acidified vase with ammonium chloride (0.1 to $0.7 \mathrm{~g})$, were added to $100 \mathrm{ml}$ of phenol solution (4 mg/L), and maintaining the contact under agitation for $2 \mathrm{~h}$ at $20^{\circ} \mathrm{C}$. After analysis of the filtered water, the concentration at stability and consequently the corresponding reduction ratio: $\mathrm{R} \%=\left(\mathrm{C}_{\mathrm{i}}-\mathrm{C}_{\mathrm{e}}\right) / \mathrm{C}_{\mathrm{i}}$ were both obtained. The evolution 


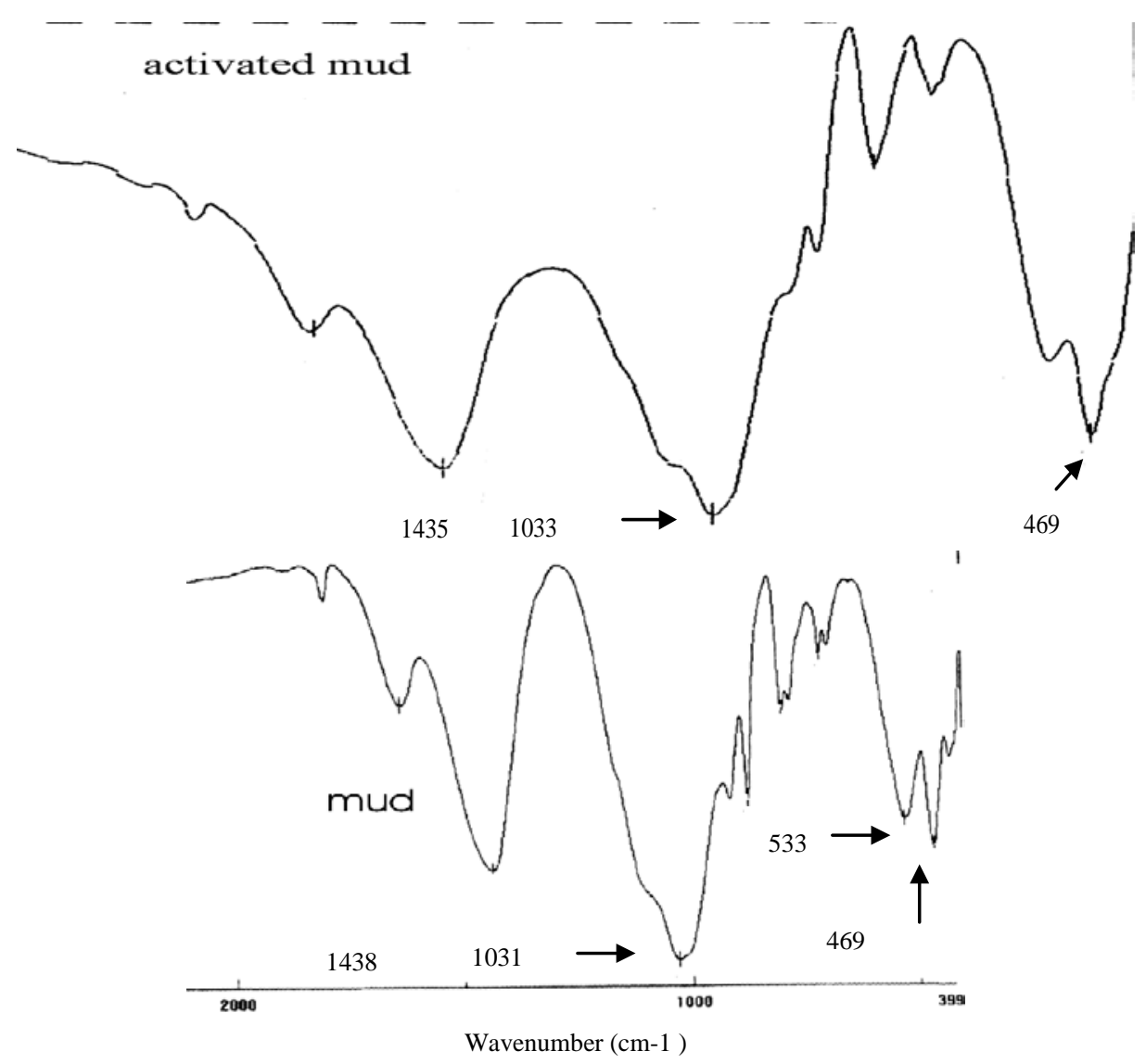

Figure 2. Infrared spectra for mud and activated mud.

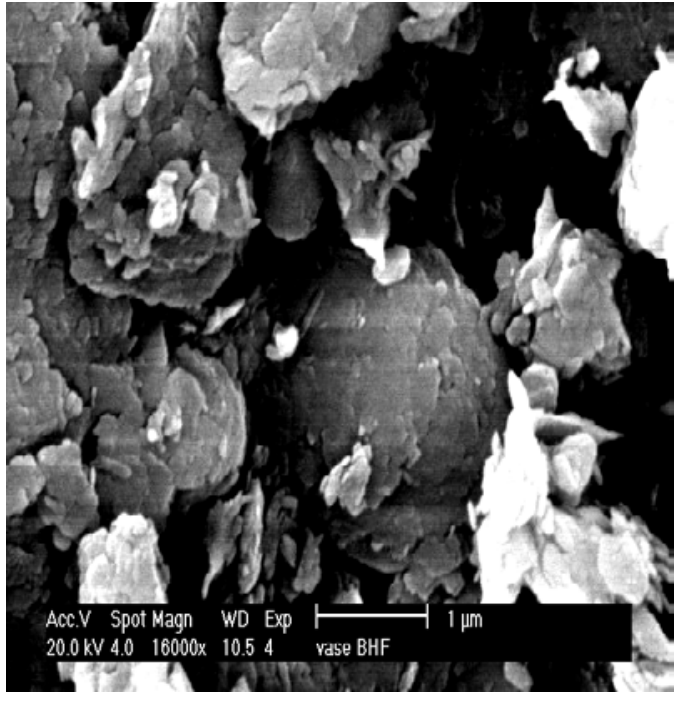

Image 1. Electron microscope with sweeping of rough mud.

in the rate of phenol elimination vs. masses of untreated mud and acidified mud is given in Figure 3. The maximum elimination rate value $75.05 \%$ has been derived for

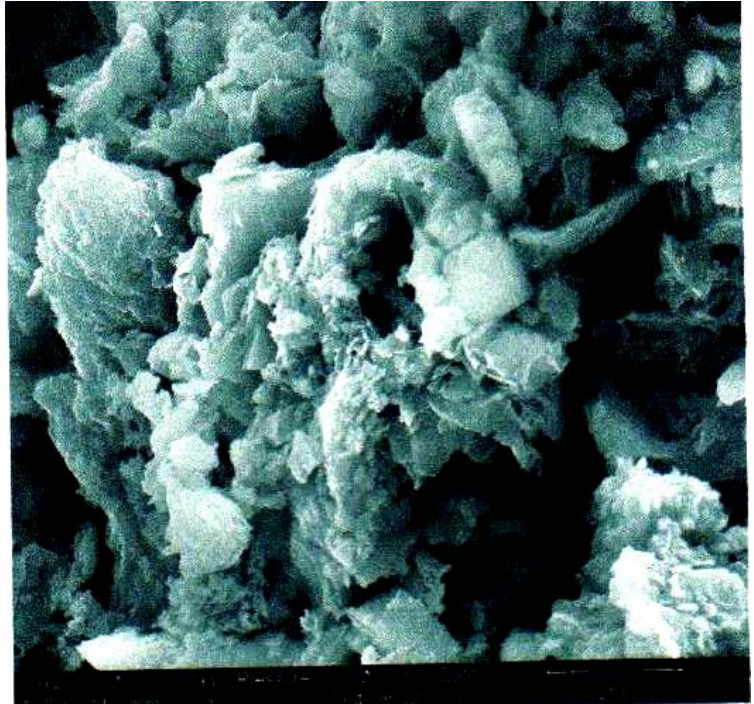

Image 2. Electron microscope with sweeping of activated mud.

a mass of activated mud equal to $0.4 \mathrm{~g}$. Beyond this mass, the curve reaches a stage indicating that the quantity of fixed phenol no longer varies. The untreated mud exhib- 
its a lower rate of phenol elimination, approx. 21.42\%. These experimental results thus justify mud activation [12-26].

\subsection{Effect of Stirring Velocity}

In order to study the influence of stirring velocity on phenol fixation Figure 4, samples were prepared by mixing $0.4 \mathrm{~g}$ of acidified mud with $100 \mathrm{ml}$ of phenol solution (4 mg/L) agitated for $120 \mathrm{~min}$ at various speeds at $20^{\circ} \mathrm{C}$. An increase in the phenol elimination rate is indeed noticeable. Faster agitation incites the diffusion of phenol molecules and their fixation onto the activated mud.

\subsection{Effect on Initial Phenol Concentration}

The adsorption data for the uptake of phenol versus contact time at different initial concentrations is presented in Figure 5. The results show that equilibrium time required for the adsorption of phenol on activated mud is almost 80 minutes. It is also seen that the remaining concentration of phenol becomes asymptotic to the time axis after 80 minutes of shaking. These results also indi-

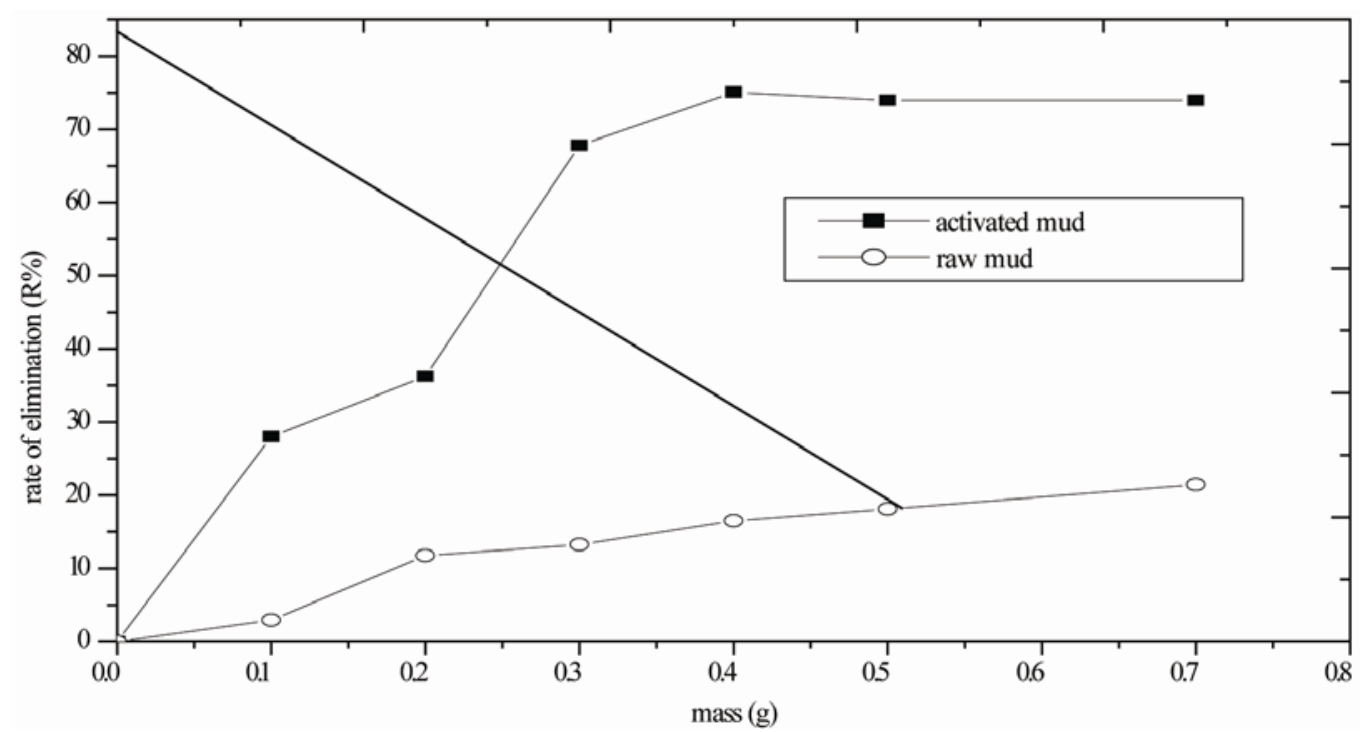

Figure 3. Fixation of phenol according to the mass of the mud and activated mud at $20^{\circ} \mathrm{C}$, [phenol] $=4 \mathrm{mg} / \mathrm{L}$.

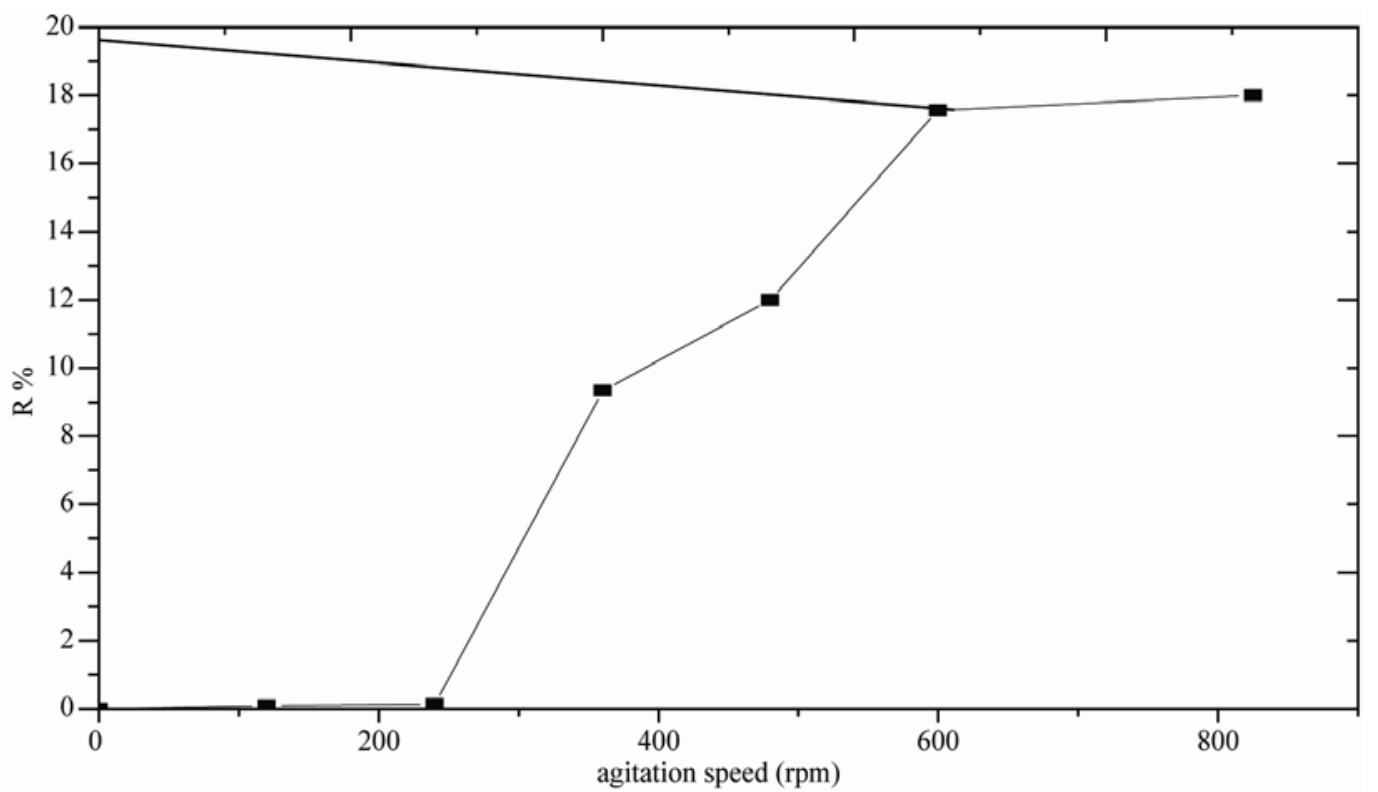

Figure 4. Effect of agitation speed to the remaining phenol at $20^{\circ} \mathrm{C}$, [phenol] $=4 \mathrm{mg} / \mathrm{L}$. 


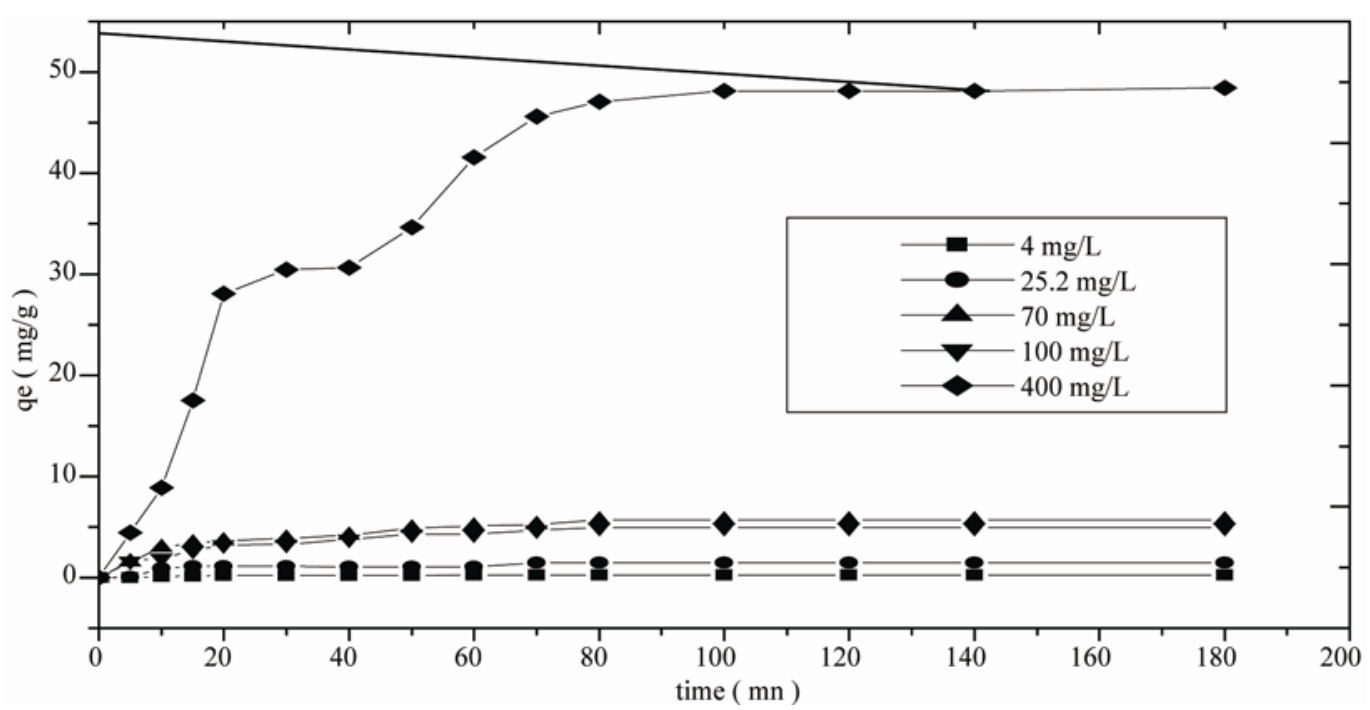

Figure 5. Effect of initial concentrations to the remaining phenol at $20^{\circ} \mathrm{C}$.

cate that the sorption process can be considered very fast because of the largest amount of phenol attached to the sorbent within the first 80 minutes of adsorption. The adsorbed amount at equilibrium $\mathrm{q}_{\mathrm{e}}$, increases according to the initial concentration of the treated phenol solution. When the initial phenol concentration is $400 \mathrm{mg} / \mathrm{L}$, the adsorbed amount at equilibrium is maximised and reaches $48.12 \mathrm{mg} / \mathrm{g}$. Fixing the phenol thus becomes more heavily favoured as the initial concentration increases. The increase in concentration enhances mass transfer, thereby exerting a force on the surface of the adsorbent and leading to an increase in phenol adsorption speed on the activated mud. Since our experimental results clearly suggest Type I isotherms [27,28].

\subsection{Adsorption Isotherm}

During the batch experiments, adsorption isotherms were used to evaluate adsorption properties. $0.4 \mathrm{~g}$ of adsorbent was mixed with $100 \mathrm{ml}$ of the aqueous solutions of various initial concentration (C0) ranges from 2 to $200 \mathrm{mg} / \mathrm{L}$ at $20^{\circ} \mathrm{C}$. A mechanical agitator at $500 \mathrm{rpm}$ was used. Suspensions shaken for $2 \mathrm{~h}$.

The curves associated to the Langmuir model and Freundlich model are represented in Figure 6 and Figure 7.

By means of the correlation coefficients obtained from the trend curves, it can be observed that the most suitable model for the adsorption of phenol by acidified sludge would be Langmuir's $\left(\mathrm{R}_{\text {Langmuir }}^{2}>\mathrm{R}^{2}\right.$ Freundlich $)$

Assuming the Langmuir isotherm model applies, the following rearrangement of Equation (2) allows the determination of Langmuir parameters:

$$
\mathrm{Q}^{0}=28.98 \mathrm{mg} / \mathrm{g} \quad \mathrm{b}=0.0066 \mathrm{~L} / \mathrm{mg} \quad \mathrm{r}^{2}=0.9811
$$

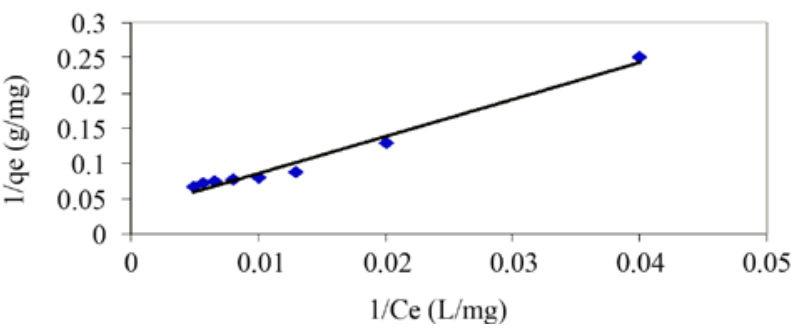

Figure 6. Isotherm at $20^{\circ} \mathrm{C}$ for phenol on activated mud. Experimental are reported as points and Langmuir model by curve.

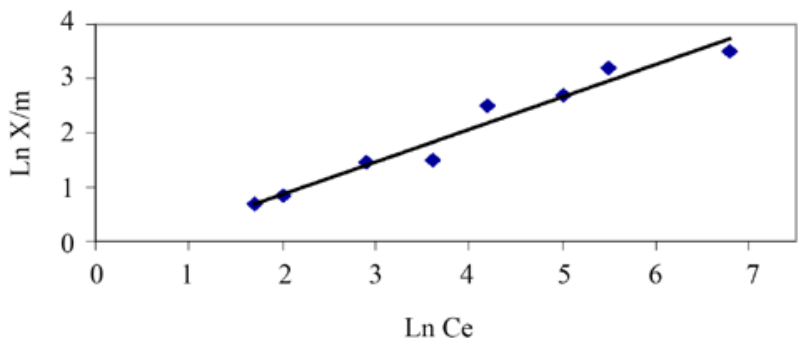

Figure 7. Isotherm at $20^{\circ} \mathrm{C}$ for phenol on activated mud. Experimental are reported as points and Freundlich model by curve.

Assuming the Freundlich isotherm model applies, the following rearrangement of Equation (3) allows the determination of Freundlich parameters:

Values of $\mathrm{n}$ and $\mathrm{K}$ were calculated from experimental data through linear regression:

$$
\mathrm{n}=1.57 \quad \mathrm{~K}=0.62 \quad \mathrm{r}^{2}=0.9580
$$

The correlation coefficient $\left(\mathrm{r}^{2}\right)$ was found to be very high in Langmuir adsorption model. The Langmuir adsorption model was found to be applicable in interpreting phenol adsorption by activated mud. 


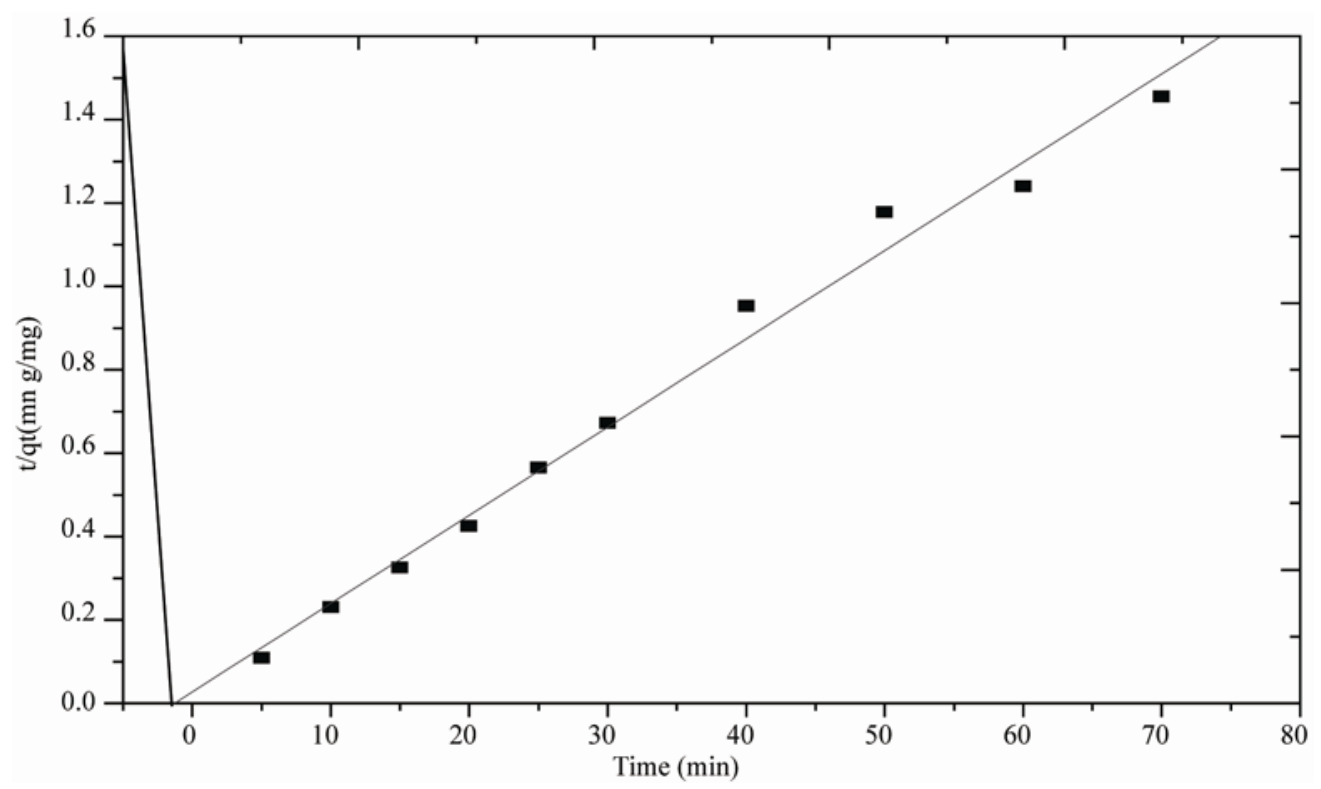

Figure 8. Pseudo-second order kinetics plot for adsorption of phenol on activated mud.

\subsection{Adsorption Kinetic Modelling}

The kinetics study has been applied to an initial phenol concentration equal to $400 \mathrm{mg} / \mathrm{L}$ and an activated sludge mass/volume ratio for the phenol solution of 3.75 $\mathrm{mg} / \mathrm{mL}$.

The pseudo second order kinetic equation was applied to the experimental data in order to investigate the sorption mechanism of phenol. Figure 8 show the plots of the linearized form of the pseudo second order model for sorption of phenol at $20^{\circ} \mathrm{C}$.

By comparing the correlation coefficients obtained for both the first- and second-order kinetic equations, it can be noted that the most suitable kinetic model for phenol adsorption is the second-order one, with an adsorption capacity of activated mud at saturation equal to:

qe $=47.1698 \mathrm{mg} / \mathrm{g}$. Correlation coefficient obtained for second-order kinetic: $r^{2}=0.9883$. The rate constant of sorption $\mathrm{K}=0.016 \mathrm{~g} / \mathrm{mg} . \mathrm{mn}$.

\section{Conclusions}

The adsorption of phenol in aqueous solution by an activated mud by ammonium chloride was investigated. Activation shows an increase in specific surface.

The isotherms and kinetics of adsorption of phenol onto mud activated chemically by ammonium chloride are studied at $20^{\circ} \mathrm{C}$. The following results are obtained:

- The amount of sorbed phenol for an initial concentration of $400 \mathrm{mg} / \mathrm{L}$ is $48.12 \mathrm{mg} / \mathrm{g}$.

- The adsorption isotherm onto activated mud is determined. The Langmuir model fits the experimental data well.

- The adsorption of phenol on activated mud was best described by the pseudo second order rate model and sorption can not been described with first order model. The adsorption capacity of activated mud at saturation was found to be $47.1698 \mathrm{mg} / \mathrm{g}$.

Consequently, mud activated chemically by ammonium chloride is successfully used as adsorbing agent and has a high adsorption capacity for phenol.

\section{References}

[1] ATSDR, “Toxicological Profiles for Phenol,” Agency for Toxic Substances and Disease Registry, Atlanta, 1989.

[2] M. S. Fountoulakis, S. N. Dokianakis and M. E. Kornaros, "Removal of Phenolics in Olive Wastewaters Using the White-Rot Fungus Pleurotus Ostreatus,” Water Research, Vol. 36, 2002, pp. 4735-4744. doi:10.1016/S0043-1354(02)00184-7

[3] S. Yun-Hwei, "Phenol Sorption by Organoclays Having Different Charge Characteristics," Colloids and Surfaces, Vol. 232, pp. 143-149.

[4] L. Gianfreda and F. Sannino, "Oxidative Transformation of Phenols in Aqueous Mixtures,” Water Research, Vol. 37, 2003, pp. 3205-3215. doi:10.1016/S0043-1354(03)00154-4

[5] O. Ferrandon, G. Mas, and M. T. Moss, "Utilisation des Argiles en Dépollution des Eaux,” Tribune de l'eau, Vol. 51, 1998, pp. 25-34.

[6] S. Peker, S. Yapar and N. Besun, "Physicochemical and Engineering Aspects," Colloids and Surfaces A, Vol. 104, 1995, pp. 249-257. doi:10.1016/0927-7757(95)03280-8

[7] T. Viraraghavan and A. Kapoor, “Adsorption of Mercury 
from Wastewater by Bentonite,” Applied Clay Science, Vol. 9, 1994, pp. 31-49. doi:10.1016/0169-1317(94)90013-2

[8] C. A. P Almeida, N. A. Debacher, A. J. Downsc, L. Cotteta and C. A. D. Mello, "Adsorption Behaviour of a Cationic Surfactant on Montmorillonite," Journal of Colloid and Interface Science, Vol. 332, 2009, pp. 46-53. doi:10.1016/S0169-1317(01)00032-1

[9] W. Zhijian, A. Ik-Sung, L. Chang-Ha, K. Jung-Hyun, G. S. Yong and L. Kangtaek, "Enhancing the Organic Dye Adsorption on Porous Xerogels," Colloids and Surfaces, Vol. 240, pp. 157-164.

[10] A Nennemann., S. Kulbach and G. Lagaly, "Entrapping Pesticides by Coagulating Smectites,” Applied Clay Science, Vol. 18, 2001, pp. 265-275. doi:10.1016/S0169-1317(01)00032-1

[11] C. Volzone and L. B. Garrido, "The Effect of Some Physicochemical and Mineralogical Properties on the $\mathrm{Na}_{2} \mathrm{CO}_{3}$ Activation of Argentine Bentonites," Applied Clay Science, Vol. 6, 1991, pp. 143-154. doi:10.1016/S0169-1317(01)00032-1

[12] A. Boukeroui and M. S. Ouali, “Activation D'une bentonite Par un Sel D'ammonium: Evolution de la Capacité D’échange et de la Surface Spécifique,” Annales de Chimie Science des Matériaux, Vol. 25, 2000, pp. 583-590.

[13] R. Mokaya, W. Jones, M. E. Davies and M. E. Whittle "Preparation of Alumina-Pillared Acid-Activated Clays and Their Use as Chlorophyll Adsorbents," Journal of Materials Chemistry, Vol. 4, 1993, pp. 381-387. doi:10.1016/S0169-1317(01)00032-1

[14] K. Nakagawa, SR. Mukaï, T. Suzuki and H. Tamon, "Gas adsorption on Activated Carbons from Mixtures of PET With Metal Salt," Carbon, Vol. 41, 2003, pp. 157-164. doi:10.1016/S0169-1317(01)00032-1

[15] P. E. Gonzalez and S. E. Villafranca, "Evolution of Surface Properties in a Bentonite as a Function of Acid and Heat Treatment," Journal of Chemical Technology and Biotechnology, Vol. 52, 1991, pp. 211-218. doi:10.1016/S0169-1317(01)00032-1

[16] E. Erde, N. Karapinar and R. J. Donat, Journal of Colloid Interface Science, Vol. 280, 2004, pp. 309-314. doi:10.1016/S0169-1317(01)00032-1

[17] G. Ozdemir and S. Yapar, "Adsorption and Desorption Behavior of Copper Ions on Namontmorillonite: Effect of Rhamnolipids and PH,” journal of Hazardous Materials, Vol. 166, 2009, pp. 1307-1313.

[18] F. Bergaya, B. K. G. Theng and G. Lagaly, "General Introduction," Clay Minerals, and Clay Science, chap.1. In: (Eds.) Handbook of Clay Science. Development of Clay
Science 1, Amsterdam, 2006, pp. 1-18.

[19] S. Guggenheim, "Summary of Recommendations of Nomenclature Committees Relevant to Clay Mineralogy," Report of the International Association for the Study of Clays (AIPEA) Nomenclature Committee, Clays and Clay Minerals, Vol.54, No. 6, 2006, pp. 761-772. doi:10.1016/S0169-1317(01)00032-1

[20] E. Srasra and M. Trabelsi-Ayedi, "Textural Properties of Acid Activated Glauconite,” Applied Clay Science, Vol.17, 2000, pp. 71-84. doi:10.1016/S0169-1317(01)00032-1

[21] M. F. Brigatti, A. Laurora, D. Malferrari, L. Medici and L. Poppi, "Adsorption of [Al (Urea) $\left.{ }_{6}\right]^{3+}$ and $\left[\mathrm{Cr}(\mathrm{Urea})_{6}\right]^{3+}$ Complexes in Vermiculite Interlayer," Applied Clay Science, Vol. 30, 2005, pp. 21-32. doi:10.1016/S0169-1317(01)00032-1

[22] S. Caillère and S. Hénin, "Minéralogie des Argiles," Masson, Paris, 1963, pp. 211-225.

[23] S. Petit, D. Righi, J. Madejova and A. Decarreau, "Interpretation of the Infrared $\mathrm{NH}_{4}^{+}$Spectrum of the $\mathrm{NH}_{4}{ }^{+}$-Clays: Application to the Evaluation of the Layer Charge," Clay Minerals, Vol. 34, 1999, pp. 543-549. doi:10.1016/S0169-1317(01)00032-1

[24] J. P. Coates, "A Practical Approach to the Interpretation of Infrared Spectra,” Ed. R.A. Meyers, Encyclopedia of Analytical Chemistry, Vol. 12, John Wiley and Sons Ltd, Chichester, UK, 2000, pp. 10815-10837.

[25] E. Joussein, S. Petit and A. Decarreau, "Une Nouvelle Méthode de Dosage des Minéraux Argileux en Mélange Par Spectroscopie IR,” Comptes Rendus de l'Académie des Sciences, Sciences de la Terre et des Planètes, Paris, Vol. 332, pp. 83-89.

[26] F. C. Wu, R. L. Tseng and R. S. Juang, "Preparation of Highly Microporous Carbons from Fir wood by $\mathrm{KOH}$ Activation for Adsorption of Dyes and Phenols from Water," Separation and Purification Technology, Vol. 47, 2005, pp. 10-19. doi:10.1016/S0169-1317(01)00032-1

[27] N. Rajic, D. Stojakovic, M. Jovanovic and N. Zabukovec Logar, "Removal of Nickel(II) Ions from Aqueous Solutions Using the Natural Clinoptilolite and Preparation of Nano-Nio on the Exhausted Clinoptilolite,” Applied Surface Science, Vol. 257, 2010, pp. 1524-1532. doi:10.1016/S0169-1317(01)00032-1

[28] C. Lu, C. Liu and Su, F, "Sorption kinetics, Thermodynamics and Competition of $\mathrm{Ni}^{2+}$ from Aqueous Solutions onto Surface Oxidized Carbon Nanotubes,” Desalination, Vol. 249, 2009, pp. 18-23. doi:10.1016/S0169-1317(01)00032-1 